\title{
Clinical and radiographic evaluation of a new stain-free tricalcium silicate cement in pulpotomies
}

\section{Suéllen Priscilla Rodrigues \\ de LIMA ${ }^{(a)}$ iD \\ Greissy Lopes dos SANTOS(b) iD \\ Antonio FERELLE(b) \\ Solange de Paula RAMOS(c) iD \\ Juliano Pelim PESSAN(a) iD \\ Cássia Cilene \\ DEZAN-GARBELINI (b)}

(a) Universidade Estadual Paulista - Unesp, Araçatuba Dental School, Department of Pediatric Dentistry, Araçatuba, SP, Brazil.

(b) Universidade Estadual de Londrina - UEL, Department of Oral Medicine and Pediatric Dentistry, Londrina, PR, Brazil.

(c) Universidade Estadual de Londrina - UEL, Center of Biological Sciences, Department of Histology, Londrina, PR, Brazil.

Declaration of Interests: The authors certify that they have no commercial or associative interest that represents a conflict of interest in connection with the manuscript.

\section{Corresponding Author:}

Suéllen Priscilla Rodrigues de Lima Silva Serra E-mail:supriscilla_@hotmail.com, supriscillarl@gmail.com

https://doi.org/10.1590/1807-3107bor-2020.vol34.0102

Submitted: April 24, 2020

Accepted for publication: June 15, 2020

Last revision: July 13, 2020

\begin{abstract}
The aim of this study was to evaluate and compare the clinical and radiographic success rates of pulpotomies in primary molars using a new stain-free tricalcium silicate cement (Bio-C Pulpo) versus a conventional white MTA (MTA Angelus) as a pulpotomy medicament for primary teeth. Seventy primary teeth in 33 patients were randomly divided into two groups, MTA Angelus $(\mathrm{n}=34)$ and Bio-C Pulpo $(n=36)$. Clinical and radiographic follow-up examinations were conducted at seven days (except radiographic follow-up), and at one, three, six and 12 months. At 12 months, the clinical success rate of the MTA Angelus group was 100 percent (28 out of 28), and the radiographic success rate was 100 percent (28 out of 28$)$. In comparison, the clinical success rate for the Bio-C Pulpo group was 100 percent (29 out of 29), and the radiographic success rate was 100 percent (29 out of 29). No significant differences were found between the groups at any follow-up evaluation. According to Fisher's exact test, a significant difference was observed between the pulpotomy agent and tooth discoloration ( $p$ < 0.001). The success rates were $100 \%$ for the Bio-C Pulpo group, with no case of discoloration, and $10.31 \%$ for the MTA Angelus group. Both MTA Angelus and Bio-C Pulp pulpotomy medicaments are appropriate options for pulpotomies in primary teeth, and enable high clinical and radiographic success rates. However, more long-term studies are required to test the new Bio-C Pulpo medicament.
\end{abstract}

Keywords: Pulpotomy; Biocompatible Materials; Randomized Controlled Trial.

\section{Introduction}

Untreated carious lesion in deciduous teeth was the $10^{\text {th }}$ most prevalent condition globally, and affected 621 million children worldwide ${ }^{1}$ in 2010, as pointed out by the Global Burden of Disease (2015). Pulpotomy is the most common treatment for carious-exposed pulps in asymptomatic primary molars. This procedure aims to maintain radicular pulp vitality or to heal the diseased coronal pulp after amputation. ${ }^{2,3,4}$ Studies comparing mineral trioxide aggregate (MTA) versus formocresol (FC) in pulpotomies of deciduous teeth attest that the latter presents superior or similar clinical and radiographic performance. ${ }^{3,5,6}$ MTA was introduced by Torabinejad in 1993. It is composed of tricalcium silicate, tricalcium aluminate, tricalcium 
oxide, silicate oxide and bismuth oxide. ${ }^{6,7}$ According to the International Agency for Research on Cancer, formaldehyde [an FC component] has carcinogenic potential, and may lead to nasopharyngeal cancer development. ${ }^{8}$ This has led clinicians to use alternative therapeutic agents that are more biocompatible than FC. ${ }^{9}$

Pulpotomy success rates of MTA are related to its biocompatibility, $3,6,10,11$ alkaline $\mathrm{pH}, 3,6,10$ antimicrobial effect, ${ }^{6,9,12,13}$ ability to maintain pulp integrity and physiological function, ${ }^{6,13}$ and its setting time in humid environments. ${ }^{3,6,11}$ It has also been found to prevent infiltration, have good sealing ability, ${ }^{6,9,11,12}$ induce hard tissue formation ${ }^{6,10}$ and promote tissue neoformation when placed in contact with dental pulp or periradicular tissues, without cytotoxic effects ${ }^{3,6,13}$ However, the difficulties in handling, the long setting time, ${ }^{6,12,14}$ and tooth discoloration have been pointed out as its main limitations. ${ }^{6,7,12,15,16}$

The cause of tooth discoloration is still unclear; however, studies have pointed to the bismuth oxide (radiopacifier agent) in its composition as being the cause. ${ }^{6,715}$ MTA was developed in a white version ${ }^{6,17}$ to minimize tooth discoloration as a clinical limitation to its use; however, studies have shown that this discoloration still occurs ${ }^{6,17,18}$ in shades ranging from white to gray, dark brown or black. ${ }^{15}$

A new stain-free tricalcium silicate cement (Bio-C Pulpo, Angelus, Londrina, PR, Brazil) has been developed with clinical and radiographic success, attributed to the color-related feature of the new material, which favors greater aesthetic appeal. ${ }^{16}$ The bismuth oxide radiopacifier agent was replaced with zirconium oxide in Bio-C Pulpo in order to minimize tooth discoloration.

The aim of this study was to evaluate and compare the clinical and radiographic success rates of pulpotomies in primary molars using a new stain-free tricalcium silicate cement (Bio-C Pulpo), versus conventional white MTA cement (MTA Angelus), as a pulpotomy medicament in primary teeth.

\section{Methodology}

This randomized, parallel, double-blind controlled clinical trial was designed to compare the clinical and radiographic success of MTA Angelus and Bio-C Pulpo cements in pulpotomies of primary teeth. The study was conducted between April 2016 and September 2017. Approval was obtained from the Research Ethics Committee on Human Behavioral Research of Londrina State University (UEL), Londrina, Paraná, Brazil, protocol number CAAE 49063315.6.0000.5231. The report was registered at the Brazilian Registry of Clinical Trials (Identifier: RBR-62wvhp).

Initially, a total of 512 children aged 3-10 years of both sexes were examined, when being screened for treatment by students in the undergraduate dental course. Those who required pulpotomy according to clinical and radiographic evaluations, were invited to participate in the study. The risks and benefits of the study were explained to their parents, and only the children whose parents gave their written informed consent were included in the study.

Patients eligible to participate were healthy and cooperative children, requiring pulpotomy in one or two primary molars, if the tooth presented signs and symptoms suggestive of reversible pulpal alteration. Inclusion criteria followed the guidelines of the American Academy of Pediatric Dentistry (AAPD) ${ }^{2}$ and the United Kingdom National Guidelines in Pediatric Dentistry, ${ }^{19}$ namely, deep carious lesion, maximum root resorption of up to $1 / 3$ of root, restorable tooth, no spontaneous pain, no tenderness to percussion or palpation, no radiographic signs of pulp degeneration, no internal/external root resorption, no widened periodontal ligament space, and no inter-radicular/furcal/periapical bone destruction. Exclusion criteria were patients who had a systemic pathology, were physically or mentally impaired, or made continuous use of drugs.

A minimum of 17.5 teeth were required in each group (total of 35 primary teeth) to detect significant differences $(80 \%$ power, two-sided $5 \%$ significance level). Since the study follow-up period was 12 months, substantial attrition was anticipated. Therefore, a total of 512 children were initially contemplated, of which 33 met the inclusion criteria (15 females, 18 males), ultimately yielding 70 primary teeth for treatment.

The teeth were randomly distributed between the two treatment groups - MTA Angelus $(n=34)$ and Bio-C Pulpo $(n=36)$ - using a random number generator (https://www.random.org) to produce a 
sequence of up to 70 numbers. The sequence was kept secret until treatment time, within sealed opaque envelopes numbered sequentially. The number was not disclosed until the post-operative bleeding stopped, at which point the tooth was assigned to the MTA Angelus group or the Bio-C Pulpo group.

The pulpotomy medicament for the MTA Angelus group was white MTA Angelus (MTA Angelus, batch \#37719, Angelus, Londrina, Brazil), and that of the Bio-C Pulpo group was a new stain-free tricalcium silicate cement (Bio-C Pulpo; Angelus, Londrina, Brazil). A plasticizer was added to the Bio-C Pulpo formulation to optimize its use as a restoration base in pediatric dentistry. The composition of each pulpotomy medicament is described in Table 1.

The pulpotomies were performed by a single pediatric dentist. Periapical radiographs were obtained for pre- and post-surgery to assess the periapical tissues regarding the most compatible technique to operate the tooth (maxillary or mandibular primary molar). The procedure included topical anesthesia ( $20 \%$ benzocaine, Benzotop, DFL, Rio de Janeiro, Brazil) on the mucosa, followed by application of local anesthesia using two percent xylocaine with one in 100,000 epinephrine (DFL, Rio de Janeiro, Brazil) injected into the tooth, as per the recommended technique for each tooth to be treated. The teeth were isolated with rubber dam. After removal of the caries lesion, the pulp chamber was accessed with a bur

Table 1. Chemical composition of white MTA Angelus and Bio-C Pulpo formulations.

\begin{tabular}{lcc}
\hline Component & MTA Angelus (\%) & Bio-C Pulpo (\%) \\
\hline Powder & & \\
Calcium silicates & $50-65$ & $50-65$ \\
Tricalcium aluminate & $5-12$ & $1-4$ \\
Calcium oxide & $1-5$ & $0.5-2$ \\
Bismuth oxide & $15-30$ & - \\
Zirconia oxide & - & $20-30$ \\
Silicon oxide & - & $2-6$ \\
Iron oxide & - & $0.05-1$ \\
Calcium fluoride & - & $1-4$ \\
Liquid & & \\
Distilled water & 100 & $60-80$ \\
Plasticizer & - & $2-7$ \\
Calcium chloride (catalyst) & - & $10-30$
\end{tabular}

(\#329), a high-speed handpiece and water spray. The coronal pulp tissue was amputated using a sterile, sharp discoid spoon excavator or sterile slow-speed round carbide bur, until the orifices of the stumps could be seen clearly without remnant tags. The cavity was irrigated with sterile saline, and initial bleeding was controlled by placing sterile cotton pellets moisturized with saline over the radicular pulp stump, and applying slight pressure for five minutes. After bleeding stopped, the tooth received either MTA Angelus or Bio-C Pulpo.

At this stage, the envelope containing the randomization sequence was opened and the designated material was placed on the pulp chamber. In the MTA Angelus group, the white MTA Angelus material was prepared according to the manufacturer's instructions and applied to the pulp chamber, and then covered by a glass ionomer base (Maxxion R, batch \# 090916, FGM Dental Products, Joinville, Brazil). In the Bio-C Pulpo group, Bio-C Pulpo was placed on the pulp chamber in an amount sufficient to build the base of the dental restoration. Lastly, all the teeth were filled with composite resin (Single Bond, batch \#685866, 3M, Sumaré, Brazil | Filtek Z250, batch \#261559, 3M, Sumaré, Brazil).

Study participants were blinded to the material used in the pulpotomy. Two professionals blinded to the treatment analyzed the radiographic outcomes. In the case of divergence, diagnosis was established by consensus. Both examiners were experts in Pediatric Dentistry with over twelveyears of experience in the field.

The clinical assessment of each tooth was performed at seven days, and one, three, six and 12 months. The radiographic assessment was performed at one, three, six and 12 months. At each follow-up visit, the treatment was considered a clinical failure if one of the following signs or symptoms was detected: spontaneous pain, tenderness to percussion or palpation, pathologic mobility, swelling, fistula, or gingival inflammation. The treatment was considered a radiographic failure if one of the following signs were detected: pathologic external root resorption, or no, self-limited or stable internal root resorption, or else periapical/furcal radiolucency.

The secondary outcome of tooth discoloration was defined as any visual change in tooth tone, 
color or translucence, as described by Jablonski and Chaplin..$^{20}$ The assessment was made at seven days and one, three, six and 12 months. The treatment was considered as a tooth discoloration failure if the tooth presented crown discoloration.

The data were analyzed by the chi-square test, at a significance level of $5 \%$ for homogeneity analysis. All the analyses were performed by the Statistical Package for Social Sciences (SPSS), version 17.0 (IBM Corporation, Armonk, USA).

\section{Results}

Seventy pulpotomies were performed in the primary molars of 33 children ( 15 females, 18 males) with a mean age and standard deviation of $5.7 \pm 1.6$ years. After the 12-month follow-up, the research was interrupted for data analysis of the first-year referrals for intervention. In the Bio-C Pulpo group, one tooth was excluded at the 3-month follow-up due to disease, one tooth was excluded at the 6-month follow-up because the participant moved away, and four teeth were excluded at the12-month follow-up because the participant did not show up for the return visit. In the MTA Angelus group, one tooth was excluded at the 3-month follow-up due to disease, two teeth were excluded at the 6-month follow-up because the participant moved away, and four teeth were excluded at the 12-month follow-up because the participant did not show up for the return visit. The flowchart with the distribution of children at the beginning of the study and at follow-up visits is shown in Figure 1.

Homogeneity of the groups was attested to by no statistically significant differences in relation to sex or age between the teeth allocated to the MTA Angelus group and the Bio-C Pulpo group. Homogeneity of tooth distribution was confirmed, since there was no significant difference between the groups in relation to the dental arch (upper or lower) or the tooth (first or second molar) (Table 2).

The clinical and radiographic success rates of the Bio-C group were $100 \%$ (29 to 29) for both outcomes, and those of the MTA Angelus group were also 100\% (28 to 28) for both outcomes, at 12 months. Two teeth presented internal resorption in the Bio-C Pulpo group, one at the 1-month and another at the 3-month follow-up, and one tooth presented internal resorption at the 6-month follow-up in the MTA Angelus group, but no reabsorption process was not detected at the 12-month follow-up for either Bio-C Pulpo or MTA Angeles. There were no significant differences in the clinical or radiographic success rates among the groups at any of the follow-up dates ( $p>0.05)$ (Table 3$)$.

According to the Fisher's exact test, a significant difference was observed between the pulpotomy agent and the tooth discoloration $(\mathrm{p}<0.001)$. The success rates at the timepoints investigated, were $100 \%$ for the Bio-C Pulpo group with no case of discoloration, and $10.31 \%$ for the MTA Angelus Group, with an increase in the proportion of cases of crown discoloration over time. No case of tooth discoloration was observed in the Bio-C Pulpo group; therefore, no relative risk could be calculated. Since the absolute risk was zero in the Bio-C Pulpo group at all follow-up timepoints, the attributable risk to tooth discoloration by MTA Angelus treatment at seven days and one, three, six and 12 months was, respectively, 32.4\% (95\%CI: $18.0 \%-50.6 \%$ ), $76.5 \%$ (95\%CI: $58.4 \%-88.6 \%$ ), $84.8 \%$ (95\%CI: 67.3\%-94.3\%), 87.5\% (95\%CI: 70.1\%-95.9\%) and 89.3\% (95\%CI: 70.6\%-97.2\%) (Table 4). The digital image shows the $1^{\text {st }}$ lower molar (tooth \#84) pulpotomized with Bio-C Pulpo, at the six-month follow-up, with no dental crown discoloration, next to the $2^{\text {nd }}$ lower molar (tooth \#85) pulpotomized with MTA Angelus at the same follow-up time, with a darkened appearance of the dental crown (Figure 2).

\section{Discussion}

This is the first study evaluating the clinical and radiographic success of a new stain-free tricalcium silicate cement (Bio-C Pulpo) for pulpotomy in primary molars. This new cement has a clinical and radiographic performance similar to that of white MTA Angelus, with no statistically significant difference. In addition, Bio-C Pulpo reflected the stability of the tooth color observed in its group, at the 12-month follow-up, unlike the MTA Angelus group. At the 12-month follow-up, the MTA Angelus group (89.3\%) presented some degree of tooth discoloration, whereas no discoloration was clinically observed for the Bio-C Pulpo group. 


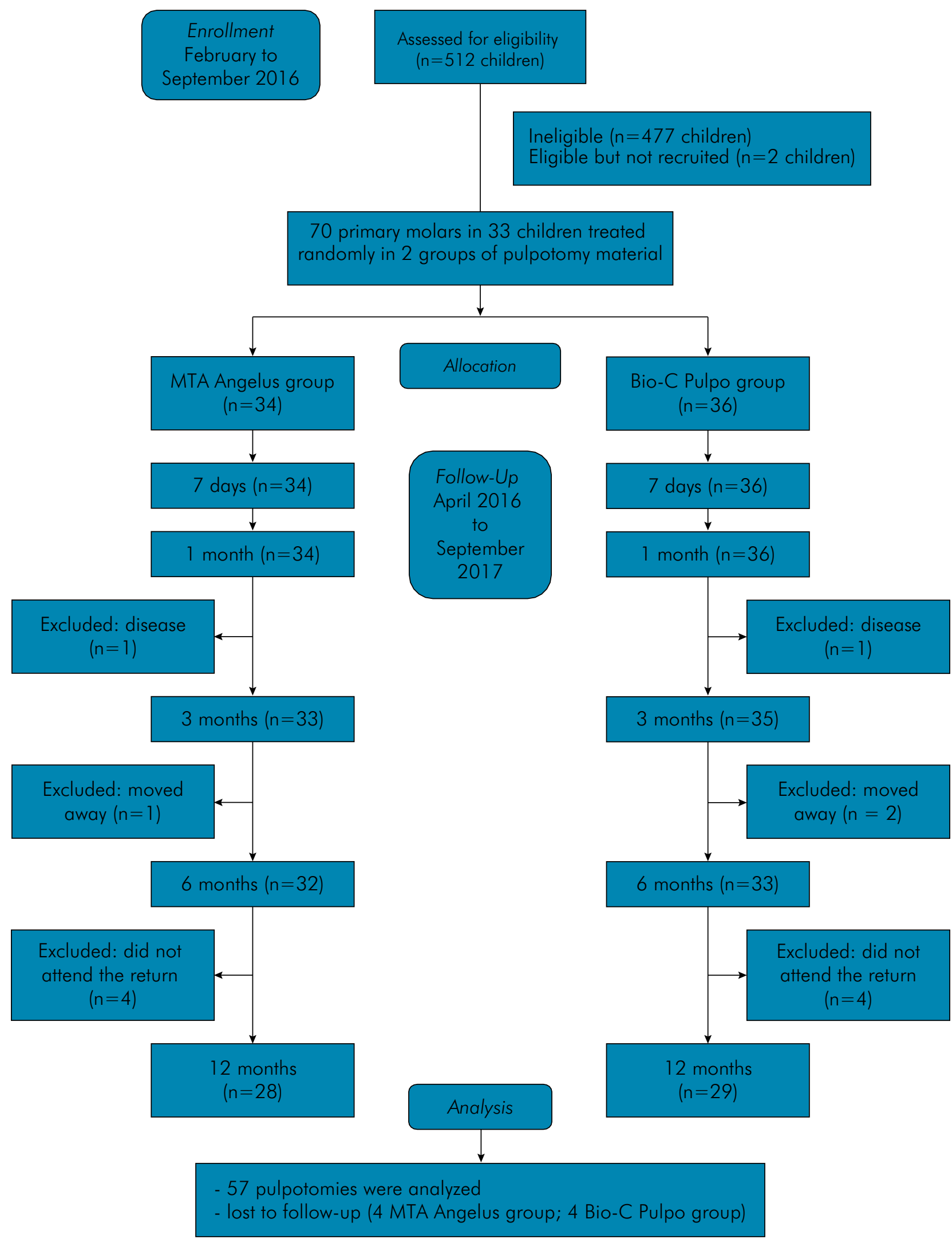

Figure 1. Flow chart of randomization and follow-up of patients according to the standards recommended by CONSORT 2010 
- Clinical and radiographic evaluation of a new stain-free tricalcium silicate cement in pulpotomies

Table 2. Patient characteristics and tooth distribution at baseline

\begin{tabular}{|c|c|c|c|}
\hline \multirow{2}{*}{ Variable } & MTA Angelus & Bio-C Pulpo & \multirow{2}{*}{ p-value } \\
\hline & $\mathrm{n}(\%)$ & $n(\%)$ & \\
\hline \multicolumn{4}{|l|}{ Sex } \\
\hline Female & $20(58.8)$ & $15(41.6)$ & $0.151^{\mathrm{a}}$ \\
\hline Male & $14(41.2)$ & $21(58.3)$ & \\
\hline Age (average; standard deviation) & $5.9 \pm 1.4$ & $5.3 \pm 1.7$ & $0.121^{b}$ \\
\hline \multicolumn{4}{|l|}{ Teeth } \\
\hline $1^{\text {st }}$ upper molar & $4(11.8)$ & 5 (13.9) & $0.769^{a}$ \\
\hline $2^{\text {nd }}$ upper molar & $5(14.7)$ & $3(8.3)$ & \\
\hline $1^{\text {st }}$ lower molar & $13(38.2)$ & $17(47.2)$ & \\
\hline $2^{\text {nd }}$ lower molar & $12(35.3)$ & $11(30.6)$ & \\
\hline
\end{tabular}

${ }^{\circ}$ chi square test; ${ }^{b}$ Student's $\dagger$ test

Table 3. Clinical (CS) and radiographic success (RS) rate (\%) following pulpotomy at the seven-day (CS), and one-, three-, six- and 12-month follow-ups.

\begin{tabular}{|c|c|c|c|c|c|c|c|c|c|c|}
\hline \multirow{3}{*}{ Group } & \multicolumn{2}{|l|}{7 days } & \multicolumn{2}{|c|}{1 month } & \multicolumn{2}{|c|}{3 months } & \multicolumn{2}{|c|}{6 months } & \multicolumn{2}{|c|}{12 months } \\
\hline & \multicolumn{2}{|l|}{$\mathrm{n}(\%)$} & \multicolumn{2}{|c|}{$n(\%)$} & \multicolumn{2}{|c|}{$n(\%)$} & \multicolumn{2}{|c|}{$n(\%)$} & \multicolumn{2}{|c|}{$n(\%)$} \\
\hline & CS & RS & CS & RS & CS & RS & CS & RS & CS & RS \\
\hline $\begin{array}{l}\text { MTA } \\
\text { Angelus }\end{array}$ & $34 / 34(100)$ & - & $34 / 34(100)$ & 34/34 (100) & 33/33 (100) & 33/33 (100) & 32/32 (100) & $31 / 321(96.8)$ & $28 / 28(100)$ & $28 / 28(100)$ \\
\hline $\begin{array}{l}\text { Bio-C } \\
\text { Pulpo }\end{array}$ & $36 / 36(100)$ & - & $36 / 36(100)$ & $35 / 361(97.2)$ & 35/35 (100) & $34 / 351(97.2)$ & 33/33 (100) & 33/33 (100) & 29/29 (100) & $29 / 29(100)$ \\
\hline
\end{tabular}

*no statistically significant difference was found between the groups at any time intervals ( $p>0.05)$. 'one internal resorption in Bio-c Pulpo at the 1 -month follow-up, and another at the 3-month follow-up; one internal resorption in MTA Angelus at the 6-month follow-up.

Table 4. Absolute and relative frequency of tooth discoloration after pulpotomy in Bio-C Pulpo and MTA Angelus groups, at the seven-day, and one-, three-, six- and 12-month follow-ups.

\begin{tabular}{|c|c|c|c|c|c|}
\hline \multirow{3}{*}{ Follow-up } & \multirow{3}{*}{ Group } & \multicolumn{2}{|c|}{ Tooth discoloration } & \multirow{3}{*}{ AR $(95 \% \mathrm{Cl})$} & \multirow{3}{*}{$p$-value* } \\
\hline & & Yes & No & & \\
\hline & & n (\%) & $n(\%)$ & & \\
\hline \multirow{2}{*}{7 days } & Bio-C Pulpo & $0(0.0)$ & $36(100.0)$ & $0.00(0.02-0.117)$ & \multirow{2}{*}{$<0.001$} \\
\hline & MTA Angelus & $11(32.4)$ & $23(67.7)$ & $0.324(0.180-0.506)$ & \\
\hline \multirow{2}{*}{1 month } & Bio-C Pulpo & $0(0.0)$ & $36(100.0)$ & $0.00(0.02-0.117)$ & \multirow{2}{*}{$<0.001$} \\
\hline & MTA Angelus & $26(76.5)$ & $8(23.5)$ & $0.765(0.584-0.886)$ & \\
\hline \multirow{2}{*}{3 months } & Bio-C Pulpo & $0(0.0)$ & $35(100.0)$ & $0.00(0.03-0.12)$ & \multirow{2}{*}{$<0.001$} \\
\hline & MTA Angelus & $28(84.8)$ & $5(15.2)$ & $0.848(0.673-0.943)$ & \\
\hline \multirow{2}{*}{6 months } & Bio-C Pulpo & $0(0.0)$ & $33(100.0)$ & $0.00(0.03-0.126)$ & \multirow{2}{*}{$<0.001$} \\
\hline & MTA Angelus & $28(87.5)$ & $4(12.5)$ & $0.875(0.701-0.959)$ & \\
\hline \multirow{2}{*}{12 months } & Bio-C Pulpo & $0(0.0)$ & $29(100.0)$ & $0.00(0.03-0.141)$ & \multirow{2}{*}{$<0.001$} \\
\hline & MTA Angelus & $25(89.3)$ & $3(10.31)$ & $0.893(0.706-0.972)$ & \\
\hline
\end{tabular}

*Fisher's exact test. AR = absolute risk

Tooth discoloration has been identified as a limitation and disadvantage of the MTA Angelus material used in pulpotomies, in view of the current aesthetic requirements for dental materials, even in primary molars. ${ }^{714,15,16,17}$ Among the factors contributing to the potential causes of discoloration, oxidation is a strong contender because of the heavy metal oxides (i.e., iron or bismuth) contained in cements. ${ }^{6,21,22}$ 


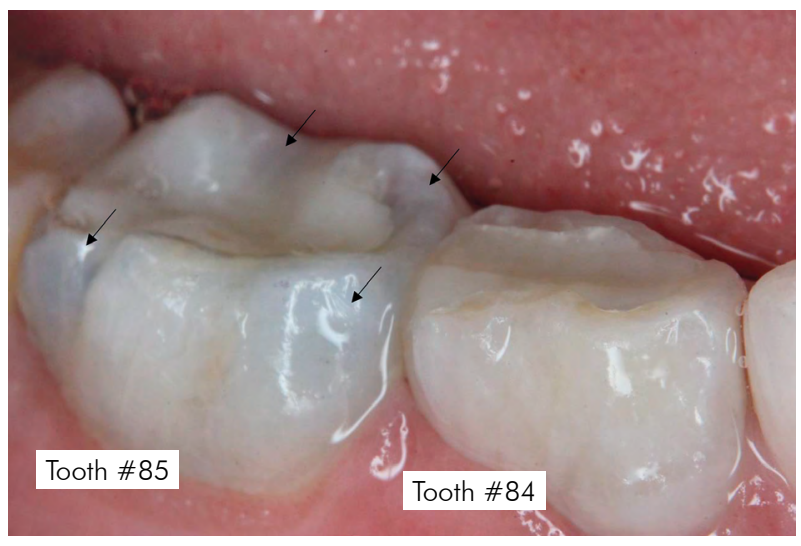

Figure 2. Example of non-discoloration of tooth \#84 ( $1^{\text {st }}$ lower molar) with Bio-C Pulpo medicament after pulpotomy, unlike tooth \#85 ( $2^{\text {nd }}$ lower molar) with MTA Angelus medicament, showing black dots on the dental crown after the six-month follow-up, indicated by the arrows.

Conventionally available MTAs contain bismuth oxide as the radiopacifier. ${ }^{6,718,23}$ Even at lower concentrations, this metal oxide has been reported as the chemical compound most commonly involved in tooth discoloration after pulpotomy treatment. ${ }^{6,7,15,18}$ The MTA discoloration associated with bismuth oxide occurs because of the reduction of this oxide in the presence of visible light or under high temperatures, leading to thermal dissociation. ${ }^{6,15,16,22}$ These reactions produce metallic bismuth (black crystal) and oxygen, giving the dental crown a darkened color, ${ }^{6,23}$ with shades ranging from gray and dark brown to black. ${ }^{15}$ Bismuth oxide can also undergo overoxidation, which can occur when it comes in contact with sodium hypochlorite, and results in a black precipitate. ${ }^{6,724}$ Another hypothesis is that tooth discoloration is a consequence of the reaction of bismuth oxide with the collagen present in the dentin organic matrix. A study was conducted by Marciano et al. ${ }^{22}$ with dental specimens treated with white MTA and stored in dark jars, immersed in water at $37^{\circ} \mathrm{C}$, free from light. It reported that bismuth oxide reacted with collagen and resulted in a grayish discoloration. ${ }^{6} \mathrm{Bi} 2 \mathrm{O} 3$ added to MTA not only causes tooth discoloration, but also has other disadvantages, including delayed hydration, prolonged setting time, and reduced material strength and durability. ${ }^{6,25}$ In the present study, the Bio-C Pulpo group contained zirconium oxide rather than bismuth oxide as a radiopacifier, and exhibited no discoloration; however the MTA Angelus group (89.3\%) contained bismuth oxide, and presented tooth discoloration at the 12-month follow-up.

The proposed Bio-C Pulpo material is a promising agent for pulpotomy in primary teeth, since removing the bismuth oxide from the original formula for MTA and replacing it with zirconium oxide did not change the clinical performance of the MTA Angelus. In this case, chromatic stability was observed after the 12-month follow-up, a phenomenon that can be attributed to using zirconium oxide radiopacifier.

Tricalcium silicate cement-based endodontic medicaments using zirconium oxide as a radiopacifier are commercially available ${ }^{6,19,25-27}$. Some examples are EndoSequence Root Repair Material (ERRM; Brasseler USA, Savannah,), Biodentine (Septodont, Saint Maur FOSES, France), ENDOCEM Zr (MARUCHI, Wonju, Korea) and RetroMTA (BioMTA, Seoul, Korea), all of which were found to promote less tooth discoloration than MTA Angelus. ${ }^{12,19}$ Zirconium oxide is an alternative to bismuth oxide, and promotes adequate radiopacity and biocompatibility, lower solubility ${ }^{6,26}$ and higher resistance to compression. ${ }^{6,26,27}$ In addition to showing color stability when exposed to light, the color of zirconium oxide is similar to that of dental structures. $^{28}$

In both groups, all the teeth subjected to pulpotomy remained asymptomatic. There was no clinical sign indicative of pulpotomy failure, such as fistula, edema, abscess, pathological mobility or tooth loss. ${ }^{29,12}$ These findings can be attributed to the biological properties of MTA, whose precise indication for treatment and technical rigor were respected. The cases selected for the present study followed the guidelines for performing pulpotomies established by $\mathrm{AAPD}^{2}$ and the UK National Clinical Guidelines in Pediatric Dentistry. ${ }^{19}$ Technical accuracy was ensured by all the procedures being performed by a single operator who was a specialist in pediatric dentistry, with experience in a practice with high patient turnover. Randomization of cases ensured that the groups were compatible in age and sex, and that dental distribution of treated molars was similar (upper or lower, first or second molars). The high clinical success rates of MTA as a pulpotomy agent are well documented. ${ }^{3,5,6,11,12,29}$ This is attributed to its biological 
properties, which include biocompatibility, ability to promote tissue neoformation when in contact with dental pulp or periradicular tissues, and lack of cytotoxic effects ${ }^{3,6,9,11}$. It also has an alkaline $\mathrm{pH}^{3}$ and an antimicrobial effect ${ }^{6,12,13}$ that make development of microorganisms unfeasible, thus eliminating the occurrence of periapical lesions, and development of fistula, edema and pathological dental mobility.

A resin was added to Bio-C Pulpo, which also allowed it to be used as a filling base, thus optimizing clinical treatment time, a factor of relevance to pediatric dentistry procedures. Because no significant differences in the clinical performance of dental fillings (such as fractures, loss of marginal integrity and secondary caries) were observed between the groups, it might be suggested that this filling base performs similarly to glass ionomer cement (as used in MTA Angelus Pulpo). However, further long-term clinical studies and laboratory investigations should be conducted to confirm these initial findings.

No statistically significant differences were detected in the radiographic findings between the groups. Two teeth presented internal resorption in the Bio-C Pulpo group, one at the 1-month and another at the 3-month follow-up, and one tooth at the 6-month follow-up in the MTA Angelus group, but this process was not detected at the 12-month follow-up in either Bio-C Pulpo or MTA Angelus. Similar findings were reported in a study by Holan et al., ${ }^{30}$ in two cases, at 25 and 38 months after pulpotomy. According to AAPD, internal resorption is not considered unsuccessful in pulpotomy, but rather, may be selflimiting and stable. The clinician should monitor the internal resorption, and remove the affected tooth if perforation causes loss of supportive bone and/or clinical signs of infection or inflammation. ${ }^{2}$

Tricalcium silicate cement-based materials containing zirconia are commercially available for endodontic purposes. ${ }^{6,25,26,27}$ However, it should be noted that our research group tested the biocompatibility of the stain-free tricalcium silicate cement (Bio-C Pulpo) in rats and minipigs prior to clinical use, and found it no different from white MTA Angelus. ${ }^{31}$ Setting time, compressive strength and radiopacity were also assessed and found to be in compliance with the standards for water-based dental cements (ANSI/ADA 96-2012). The results were satisfactory, with a setting time of about $12 \mathrm{~min}$ and a compressive strength of 89.3 $\mathrm{MP}$. Both the setting time and radiopacity of Bio-C Pulpo cement were $8.0 \mathrm{~mm}$ on the $\mathrm{Al}$ scale, hence, in compliance with ANSI / ADA standard \#96:2012, according to which acceptable radiopacity should be greater than $4 \mathrm{~mm} \mathrm{Al} .^{32}$

Pulpotomy success occurs when the root pulp remains asymptomatic, without any clinical signs or symptoms, such as sensitivity, pain or swelling, and there is no radiographic evidence of pathologic external root resorption. 2,9,12 The results of our study support that replacement of bismuth oxide by zirconium oxide causes less tooth discoloration, without affecting the clinical and radiographic success of pulpotomies of primary molars.

\section{Conclusions}

In conclusion, both MTA Angelus and Bio-C Pulpo pulpotomy medicaments are appropriate options for pulpotomies in primary teeth, with high clinical and radiographic success rates. However, more long-term studies are required to test the new Bio-C Pulpo medicament.

\section{Acknowledgments}

The authors would like to thank Dr. Farli Carrilho Boer and Dr. Marília Franco Punhagui, UEL-Department of Oral Medicine and Pediatric Dentistry, for helping perform the radiographic analyses.

\section{References}

\footnotetext{
1. Kassebaum NJ, Bernabé E, Dahiya M, Bhandari B, Murray CJ, Marcenes W. Global burden of untreated caries: a systematic review and metaregression. J Dent Res. 2015 May;94(5):650-8. https://doi.org/10.1177/0022034515573272

2. American Academy of Pediatric Dentistry. Guideline on pulp therapy for primary and immature permanent teeth. Pediatr Dent. 2009;31:179-186.
} 
3. Smaïl-Faugeron V, Glenny AM, Courson F, Durieux P, Muller-Bolla M, Fron Chabouis H. Pulp treatment for extensive decay in primary teeth. Cochrane Database Syst Rev. 2018 May;5:CD003220. https://doi.org/10.1002/14651858.CD003220.pub3

4. Olatosi $O O$, Sote EO, Orenuga OO. Effect of mineral trioxide aggregate and formocresol pulpotomy on vital primary teeth: a clinical and radiographic study. Niger J Clin Pract. 2015 Mar-Apr;18(2):292-6. https://doi.org/10.4103/1119-3077.151071

5. Sonmez D, Sari S, Cetinbaş T. A Comparison of four pulpotomy techniques in primary molars: a long-term follow-up. J Endod. 2008 Aug;34(8):950-5. https://doi.org/10.1016/i.joen.2008.05.009

6. De Deus G, Camilleri J, Primus CM, Duarte MA, Bramante CM. Introduction to mineral trioxide aggregate. Berlin: Springer; 2014.

7. Alsanouni M, Bawazir OA. A randomized clinical trial of NeoMTA plus in primary molar pulpotomies. Pediatr Dent. 2019 MarApr;41(2):107-11.

8. Rousseau MC, Straif K, Siemiatycki J. IARC carcinogen update. Environ Health Perspect. 2005 Sep;113(9):A580-1. https://doi.org/10.1289/ehp.113-a580

9. Bani M, Aktaş N, Çınar Ç, Odabaş ME. The clinical and radiographic success of primary molar pulpotomy using Biodentine ${ }^{\mathrm{TM}}$ and mineral trioxide aggregate: a 24 -month randomized clinical trial. Pediatr Dent. 2017 Jul;39(4):284-8.

10. Marghalani AA, Omar S, Chen JW. Clinical and radiographic success of mineral trioxide aggregate compared with formocresol as a pulpotomy treatment in primary molars: a systematic review and meta-analysis. J Am Dent Assoc. 2014 Jul;145(7):714-21. https://doi.org/10.14219/jada.2014.36

11. Celik B, Ataç AS, Cehreli ZC, Uysal S. A randomized trial of mineral trioxide aggregate cements in primary tooth pulpotomies. J Dent Child (Chic). 2013 Sep-Dec;80(3):126-32.

12. Çelik BN, Mutluay MS, Arıkan V, Sarı Ş. The evaluation of MTA and Biodentine as a pulpotomy materials for carious exposures in primary teeth. Clin Oral Investig. 2019 Feb;23(2):661-6. https://doi.org/10.1007/s00784-018-2472-4

13. Peng L, Ye L, Tan H, Zhou X. Evaluation of the formocresol versus mineral trioxide aggregate primary molar pulpotomy: a meta-analysis. Oral Surg Oral Med Oral Pathol Oral Radiol Endod. 2006 Dec;102(6):e40-4. https://doi.org/10.1016/i.tripleo.2006.05.017

14. Akbari M, Rouhani A, Samiee S, Jafarzadeh H. Effect of dentin bonding agent on the prevention of tooth discoloration produced by mineral trioxide aggregate. Int J Dent. 2012;2012:563203. https://doi.org/10.1155/2012/563203

15. Niu LN, Watson D, Thames K, Primus CM, Bergeron BE, Jiao K, et al. Effects of a discoloration-resistant calcium aluminosilicate cement on the viability and proliferation of undifferentiated human dental pulp stem cells. Sci Rep. 2015 Nov; $5(1): 17177$. https://doi.org/10.1038/srep17177

16. loannidis K, Mistakidis I, Beltes P, Karagiannis V. Spectrophotometric analysis of crown discoloration induced by MTA-and ZnOE-based sealers. J Appl Oral Sci. 2013 Mar-Apr;21(2):138-44. https://doi.org/10.1590/1678-7757201302254

17. Bortoluzzi EA, Araújo GS, Guerreiro Tanomaru JM, Tanomaru-Filho M. Marginal gingiva discoloration by gray MTA: a case report. J Endod. 2007 Mar;33(3):325-7. https://doi.org/10.1016/i.joen.2006.09.012

18. Vallés M, Mercadé M, Duran-Sindreu F, Bourdelande JL, Roig M. Color stability of white mineral trioxide aggregate. Clin Oral Investig. 2013 May;17(4):1155-9. https://doi.org/10.1007/s00784-012-0794-1

19. Llewelyn DR; Faculty of Dental Surgery, Royal College of Surgeons. UK National Clinical Guidelines in Paediatric Dentistry. The pulp treatment of the primary dentition. Int J Paediatr Dent. 2000 Sep;10(3):248-52.

20. Jablonski NG, Chaplin G. The evolution of human skin coloration. J Hum Evol. 2000 Jul;39(1):57-106. https://doi.org/10.1006/jhev.2000.0403

21. MoØy】ska J, Metlerski M, Lipski M, Nowicka A. Tooth discoloration induced by different calcium silicate-based cements: A systematic review of in vitro studies. J Endod. 2017 Oct;43(10):1593-601. https://doi.org/10.1016/i.joen.2017.04.002

22. Marciano MA, Costa RM, Camilleri J, Mondelli RF, Guimarães BM, Duarte MA. Assessment of color stability of white mineral trioxide aggregate angelus and bismuth oxide in contact with tooth structure. J Endod. 2014 Aug;40(8):1235-40. https://doi.org/10.1016/i.joen.2014.01.044

23. Camilleri J, Pitt Ford TR. Mineral trioxide aggregate: a review of the constituents and biological properties of the material. Int Endod J. 2006 Oct;39(10):747-54. https://doi.org/10.1111/j.1365-2591.2006.01135.x

24. Camilleri J. Color stability of white mineral trioxide aggegate in contact with hypochlorite solution. J Endod. 2014 Mar;40(3):436-40. https://doi.org/10.1016/i.joen.2013.09.040

25. Li Q, Deacon AD, Coleman NJ. The impact of zirconium oxide nanoparticles on the hydration chemistry and biocompatibility of white Portland cement. Dent Mater J. 2013;32(5):808-15. https://doi.org/10.4012/dmi.2013-113

26. Duarte MAH, Oliveira El Kadre GD, Vivan RR, Guerreiro-Tanomaru JMG, Tanomaru Filho M, de Moraes IG. Radiopacity of portland cement associated with different radiopacifying agents. J Endod. 2009 May;35(5):737-40. https://doi.org/10.1016/i.joen.2009.02.006

27. Viapiana R, Flumignan DL, Guerreiro-Tanomaru JM, Camilleri J, Tanomaru-Filho M. Physicochemical and mechanical properties of zirconium oxide and niobium oxide modified Portland cement-based experimental endodontic sealers. Int Endod J. 2014 May;47(5):437-48. https://doi.org/10.1111/iej.12167 
- Clinical and radiographic evaluation of a new stain-free tricalcium silicate cement in pulpotomies

28. Sanz O, Haro-Poniatowski E, Gonzalo J, Fernández Navarro JM. Influence of the melting conditions of heavy metal oxide glasses containing bismuth oxide on their optical absorption. J Non-Cryst Solids. 2006;352(8):761-8. https://doi.org/10.1016/j.jnoncrysol.2006.02.002

29. Hutcheson C, Seale NS, McWhorter A, Kerins C, Wright J. Multi-surface composite vs stainless steel crown restorations after mineral trioxide aggregate pulpotomy: a randomized controlled trial. Pediatr Dent. 2012 Nov-Dec;34(7):460-7.

30. Holan G, Eidelman E, Fuks AB. Long-term evaluation of pulpotomy in primary molars using mineral trioxide aggregate or formocresol. Pediatr Dent. 2005 Mar-Apr;27(2):129-36.

31. Cosme-Silva L, Gomes-Filho JE, Benetti F, Dal-Fabbro R, Sakai VT, Cintra LT, et al. Biocompatibility and immunohistochemical evaluation of a new calcium silicate-based cement, Bio-C Pulpo. Int Endod J. 2019 May;52(5):689-700. https://doi.org/10.1111/iej.13052

32. American Dental Association. Council on Scientific Affairs. American National Standard/American Dental Association Specification No 96: Dental water-based cements. Chicago: American Dental Association; 2012. 